Supporting Information

\title{
Unprecedented Strength Polysiloxane-Based Polyurethane for 3D Printing and Shape Memory
}

Wencai Wang ${ }^{1,2,3}$, Siao Sun ${ }^{l}$, Shikai $\mathrm{Hu}^{1,2,3^{*}}$, Bin Yang ${ }^{l}$, Shaoyun He $\mathrm{e}^{l}$, Runguo Wang $^{1,2,3}$, Liqun Zhang ${ }^{1,2,3 *}$

${ }^{1}$ Key Laboratory of Beijing City on Preparation and Processing of Novel Polymer Materials, Beijing University of Chemical Technology, Beijing, 100029, China

${ }^{2}$ Beijing Engineering Research Center of Advanced Elastomers, Beijing University of Chemical Technology, Beijing, 100029, China

${ }^{3}$ Engineering Research Center of Elastomer Materials on Energy Conservation and Resources, Ministry of Education, Beijing, 100029, China

* Corresponding author:

skhu@mail.buct.edu.cn (Shikai Hu);

zhanglq@mail.buct.edu.cn (Liqun Zhang) 
Table S1. Compositions of the samples.

\begin{tabular}{lcccc}
\hline Sample code & $\begin{array}{c}\text { Mn of PDMS- } \\
\text { polyol }\end{array}$ & $\begin{array}{c}\text { Molar ratio } \\
\text { PDMS-polyol: IPDI: BDO }\end{array}$ & $\begin{array}{c}\text { HS content } \\
(\%)\end{array}$ & $\begin{array}{c}\text { Average HS molecular } \\
\text { weigh }\end{array}$ \\
\hline PDMS1K-28 & 1000 & $1: 1: 0$ & 28 & 396 \\
PDMS2K-19 & 2000 & $1: 1: 0$ & 19 & 396 \\
PDMS2K-23 & 2000 & $1: 1.3: 0.3$ & 23 & 490 \\
PDMS2K-28 & 2000 & $1: 1.8: 0.8$ & 28 & 646 \\
PDMS2K-33 & 2000 & $1: 2.3: 1.3$ & 33 & 802 \\
PDMS2K-39 & 2000 & $1: 3.1: 2.1$ & 39 & 1052 \\
PDMS3K-28 & 3000 & $1: 3.5: 2.5$ & 28 & 1177 \\
\hline
\end{tabular}

(a)

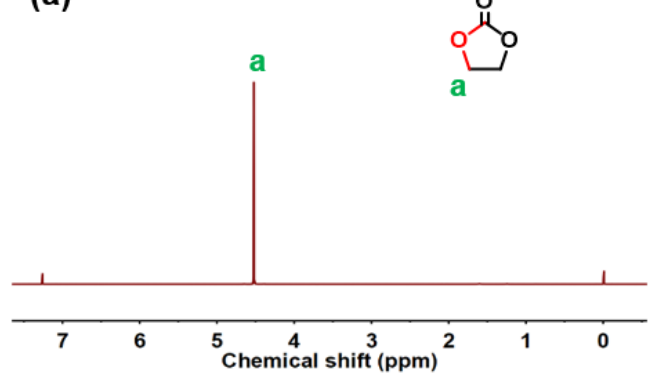

(c)

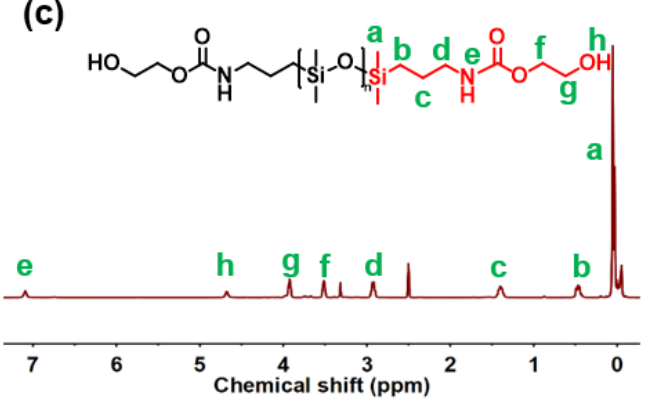

(b)
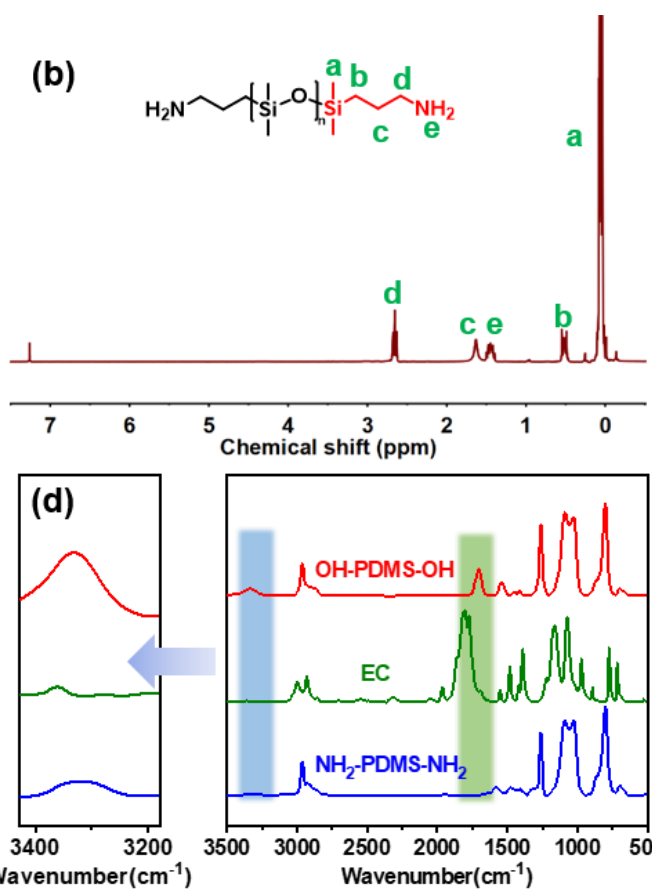

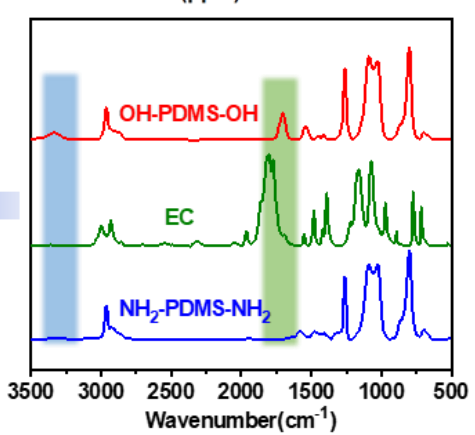

Figure S1. ${ }^{1} \mathrm{H}$ NMR spectra of a) the EC that uses chloroform-d $\left(\mathrm{CDCL}_{3}\right)$ as a solvent and b) the $\mathrm{H}_{2} \mathrm{~N}-\mathrm{PDMS}-\mathrm{NH}_{2}$ that uses chloroform-d $\left(\mathrm{CDCL}_{3}\right)$ as a solvent with an $M_{n}$ value of 1000. c) Corresponding HO-PDMS-OH that uses dimethyl sulfoxide (DMSO) as a solvent. d) FTIR spectra of HO-PDMS-OH, EC, and $\mathrm{H}_{2} \mathrm{~N}-\mathrm{PDMS}-\mathrm{NH}_{2}$. The local amplification at $3170-3440 \mathrm{~cm}^{-1}$ confirms the presence of $\mathrm{N}-\mathrm{H}$ in $\mathrm{HO}-\mathrm{PDMS}-\mathrm{OH}$ and the presence of $-\mathrm{NH}_{2}$ in $\mathrm{H}_{2} \mathrm{~N}-\mathrm{PDMS}-\mathrm{NH}_{2}$. 

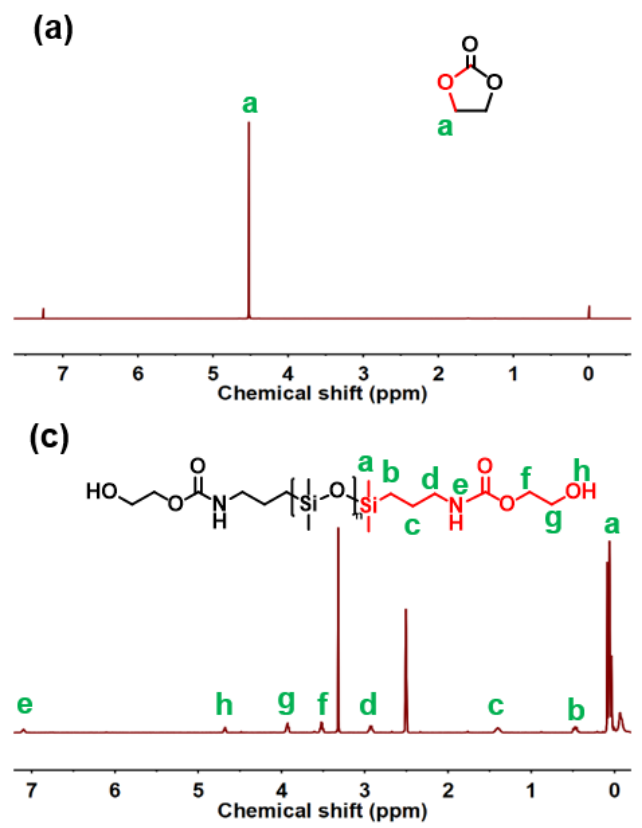

(b)
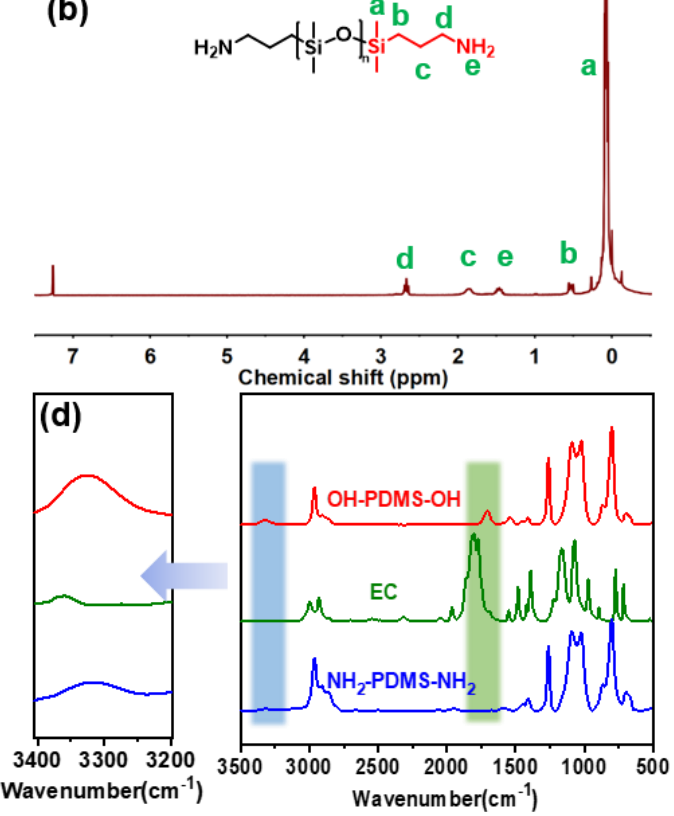

Figure S2. ${ }^{1} \mathrm{H}$ NMR spectra of the a) EC that uses chloroform-d $\left(\mathrm{CDCL}_{3}\right)$ as a solvent and the b) $\mathrm{H}_{2} \mathrm{~N}-\mathrm{PDMS}-\mathrm{NH}_{2}$ that uses chloroform-d $\left(\mathrm{CDCL}_{3}\right)$ as a solvent with an $M_{n}$ value of 3000. c) Corresponding HO-PDMS-OH that uses dimethyl sulfoxide (DMSO) as a solvent. d) FTIR spectra of HO-PDMS-OH, EC, and $\mathrm{H}_{2} \mathrm{~N}-\mathrm{PDMS}-\mathrm{NH}_{2}$. The local amplification at $3200-3400 \mathrm{~cm}^{-1}$ confirms the presence of N-H in HO-PDMS-OH and the presence of $-\mathrm{NH}_{2}$ in $\mathrm{H}_{2} \mathrm{~N}-\mathrm{PDMS}-\mathrm{NH}_{2}$.

(a)

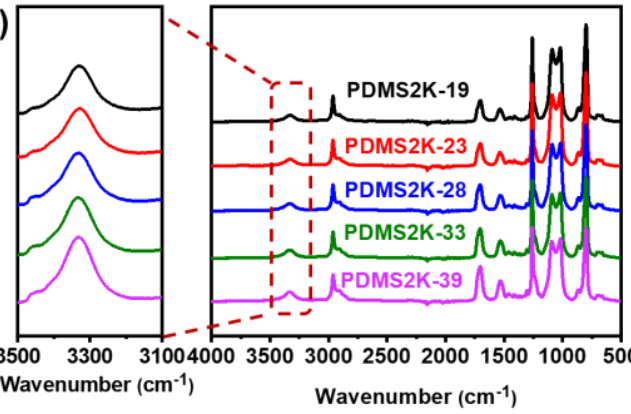

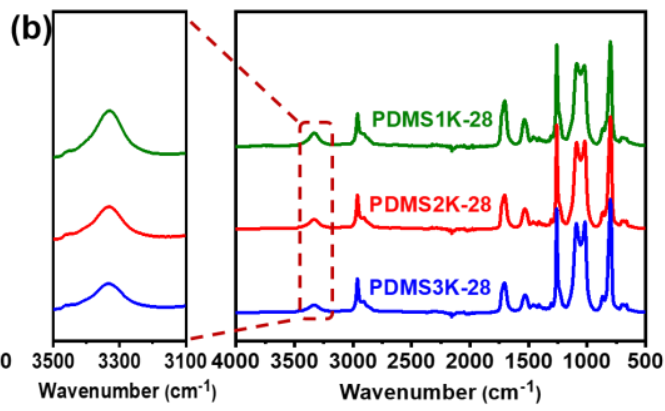

Figure S3. FTIR spectra of Si-TPUs with a) different HS contents and b) different $M_{n}$ of SS. The intensities of the $\mathrm{N}-\mathrm{H}$ and $\mathrm{C}=\mathrm{O}$ peaks gradually strengthened with the increase in the HS content and the decrease in $M_{n}$ of SS. 
Table S2. Summary of the molecular weights $\left(M_{n}\right.$ and $\left.M_{w}\right)$ and polydispersity indices of Si-TPUs.

\begin{tabular}{lccc}
\hline Sample code & $M_{n}\left(10^{4}\right)$ & $M_{w}\left(10^{4}\right)$ & $\Xi$ \\
\hline PDMS1K-28 & 4.9 & 13.4 & 2.7 \\
PDMS2K-19 & 4.5 & 8.8 & 1.9 \\
PDMS2K-23 & 5.8 & 12.3 & 2.1 \\
PDMS2K-28 & 5.0 & 10.5 & 2.1 \\
PDMS2K-33 & 5.6 & 11.7 & 2.1 \\
PDMS2K-39 & 7.5 & 17.9 & 2.4 \\
PDMS3K-28 & 6.2 & 12.3 & 2.0 \\
\hline
\end{tabular}

(a)

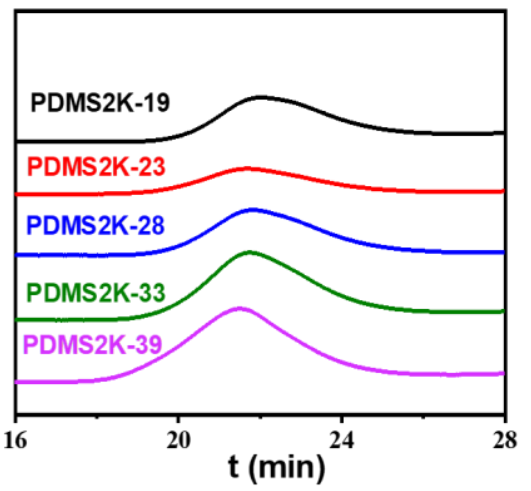

(b)

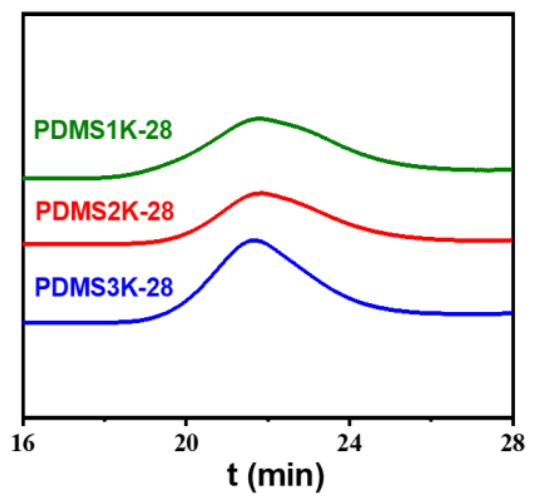

Figure S4. GPC curves of the Si-TPUs with a) different HS contents and b) different $M_{n}$ of SS. The number-average molecular weight and molecular weight distribution of the samples were measured using gel permeation chromatography (GPC, Water Breeze)). Tetrahydrofuran (THF) was used as an eluent with a flow rate of $1 \mathrm{~mL}$ $\min ^{-1}$. 


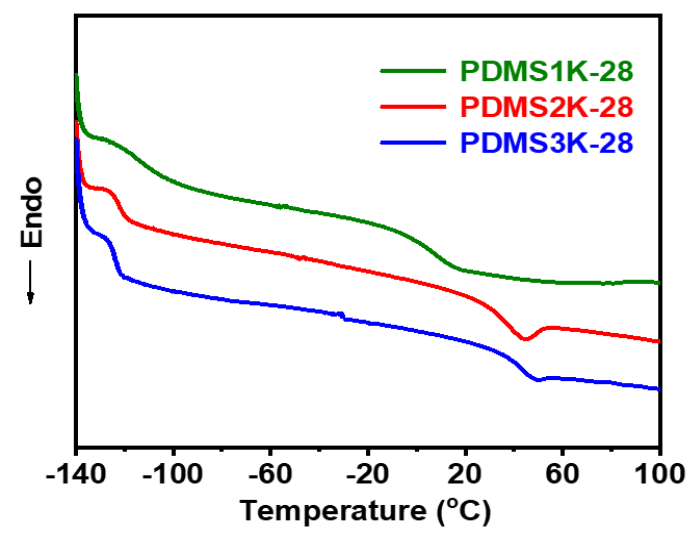

Figure S5. DSC curves of the Si-TPUs with different $M_{n}$ of SS, ranging from -140 to $100^{\circ} \mathrm{C}$.

(a)

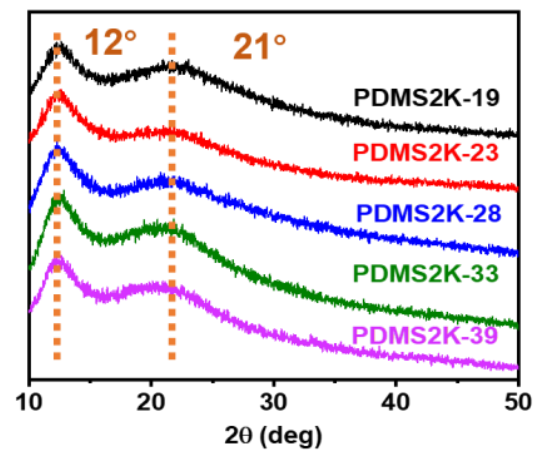

(b)

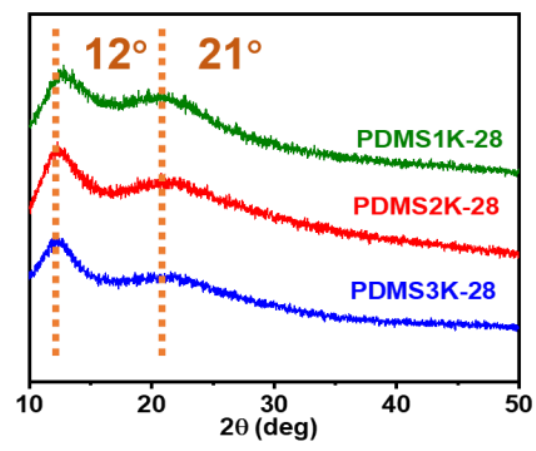

Figure S6. WAXD curves of the Si-TPUs with a) different HS contents and b)

different $M_{n}$ of SS. The curves show the amorphous structure of Si-TPUs. Wide angle X-ray diffraction (WAXD) patterns were collected on a Rigaku 2500VB2+PC X-ray diffractometer from Japan, using the scanning angle ranged from $5^{\circ}$ to $90^{\circ}$. 

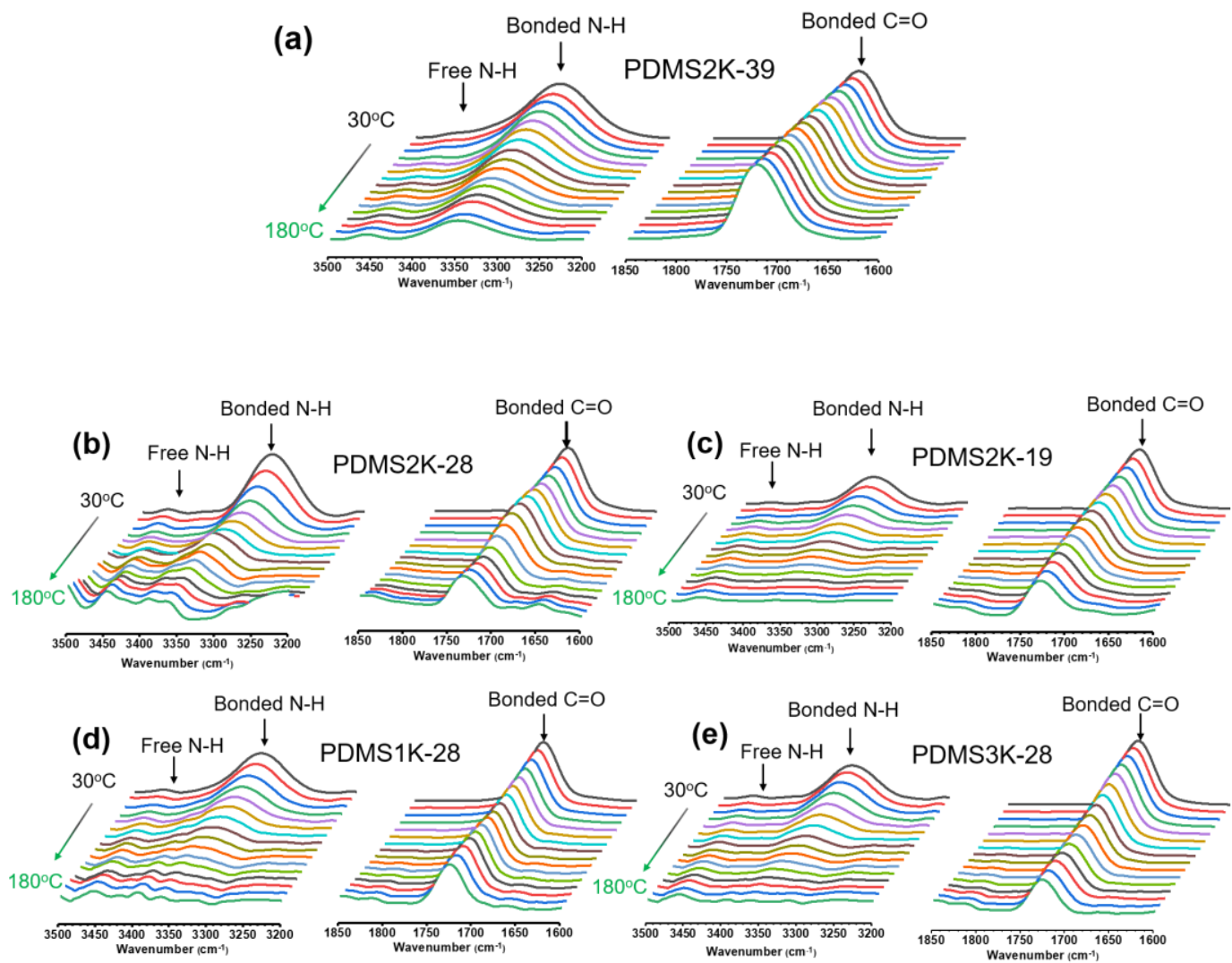

Figure S7. FTIR spectra of $\mathrm{N}-\mathrm{H}$ and $\mathrm{C}=\mathrm{O}$ from a) PDMS2K-39, b) PDMS2K-28, c) PDMS2K-19, d) PDMS1K-28, and e) PDMS3K-28 from 30 to $180^{\circ} \mathrm{C}$ during the heating process. The peak intensity at $3330-3500 \mathrm{~cm}^{-1}$ decreased and the intensity at $3400-3600 \mathrm{~cm}^{-1}$ increased with the increase in temperature, showing the transition from the bonded N-H to free N-H. Furthermore, the peak displayed a blueshift, and the intensity decreased from 30 to $180^{\circ} \mathrm{C}$, showing the dissociation of the bonded $\mathrm{C}=\mathrm{O}$.

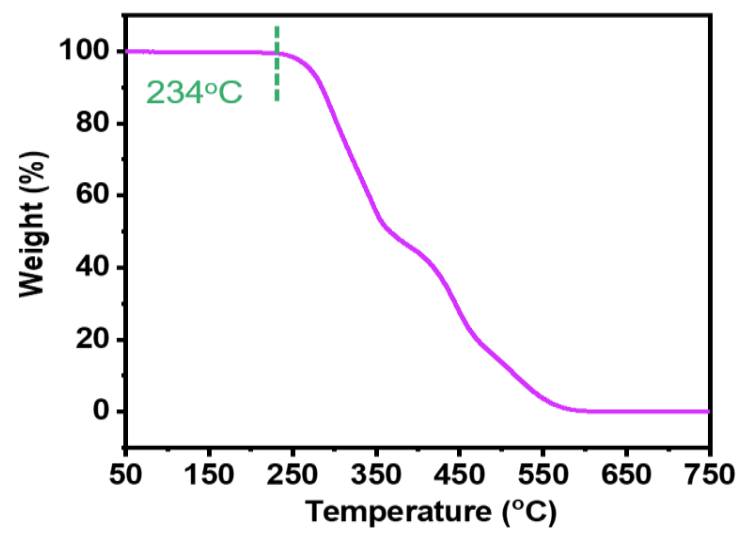

Figure S8. TGA curve of PDMS2K-39. The Si-TPUs did not degrade when the temperature increased to $180^{\circ} \mathrm{C}$. Thermogravimetric analysis (TGA) measurements 
were conducted using a TA Instruments $\mathrm{TGA} / \mathrm{DSC}^{+}$thermogravimetric analyzer (Mettler-Toledo, The Swiss). The samples were heated from 40 to $800^{\circ} \mathrm{C}$ at a rate of $10^{\circ} \mathrm{C} \min ^{-1}$ under a nitrogen atmosphere.

(a)

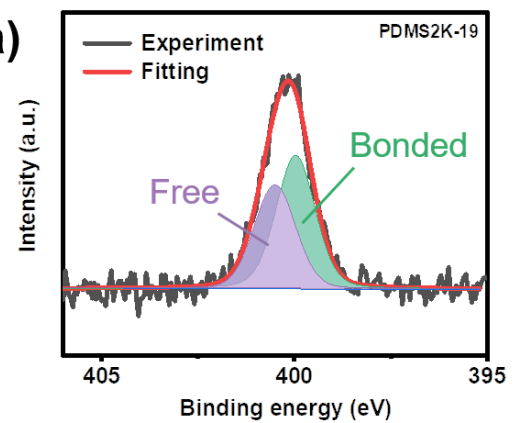

(c)

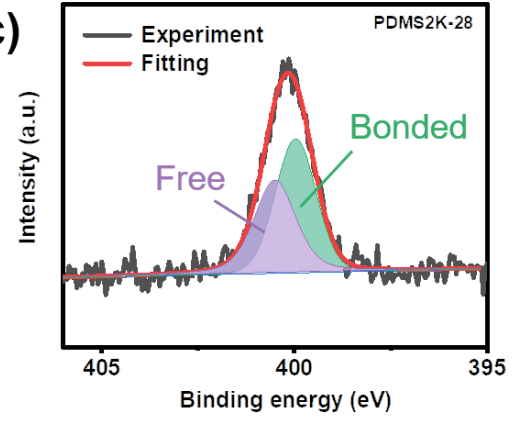

(b)

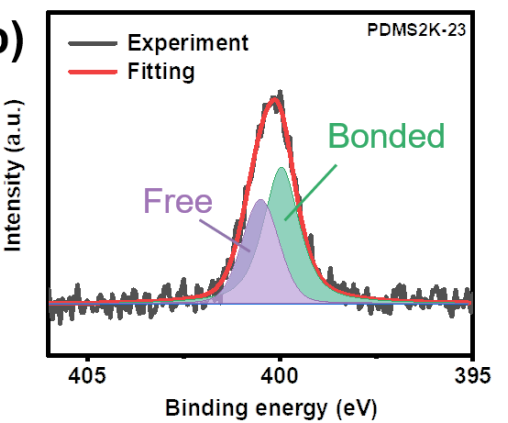

(d)

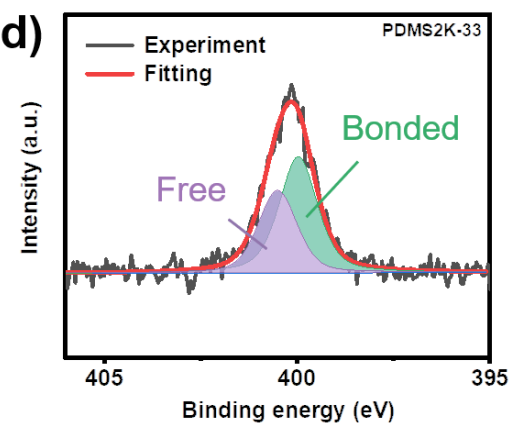

Figure S9. Narrow-scan XPS spectra of the Si-TPUs with different HS contents. a) PDMS2K-19, b) PDMS2K-23, c) PDMS2K-28, d) PDMS2K-33.

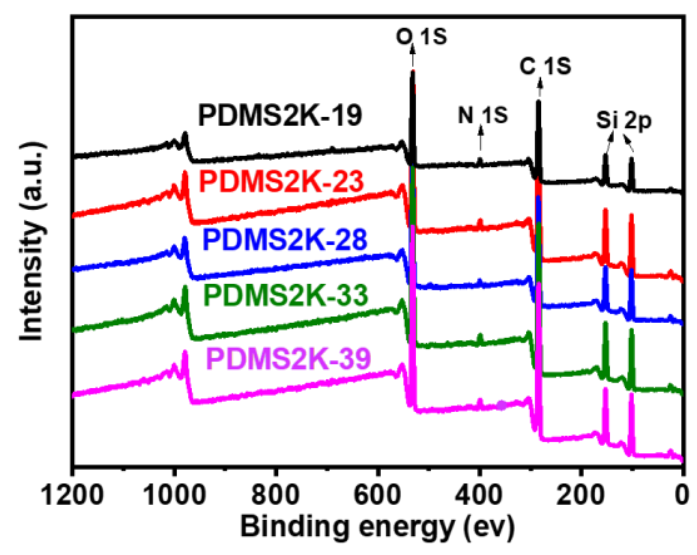

Figure S10. Wide-scan XPS spectra of the Si-TPUs with different HS contents. 


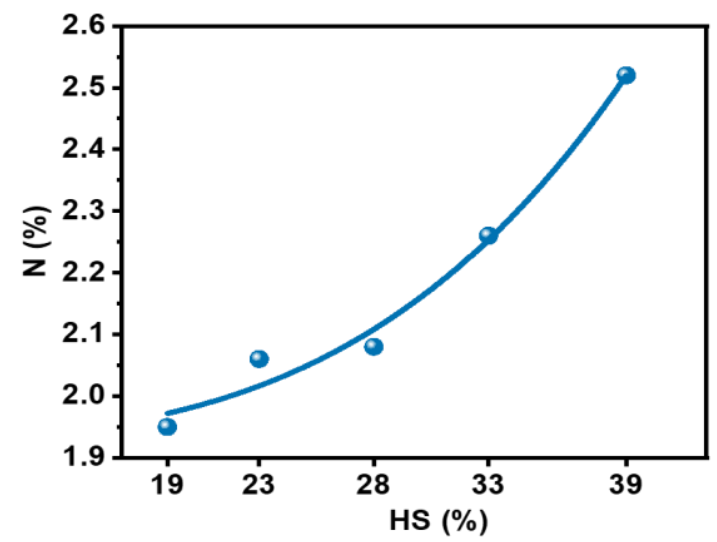

Figure S11. Fitting curve of the atomic percentage of $\mathrm{N}$ and the HS content from the wide-scan XPS.
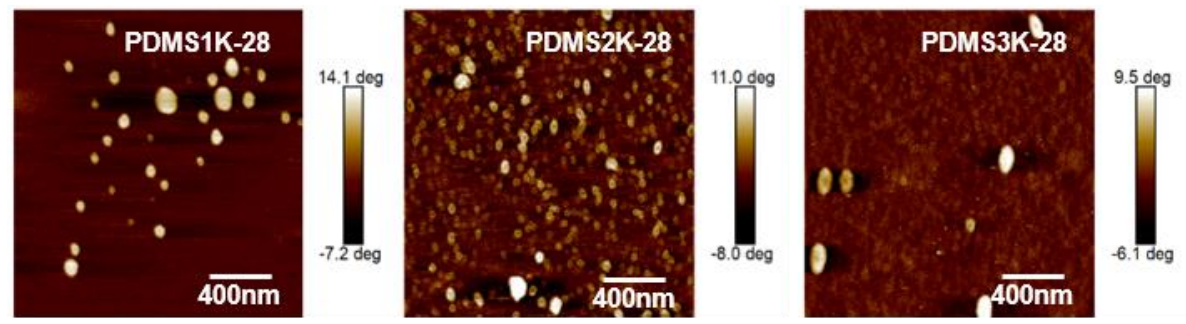

Figure S12. AFM phase images of the Si-TPUs with different $M_{n}$ of SS. The images indicate the existence of phase separation.

(a)
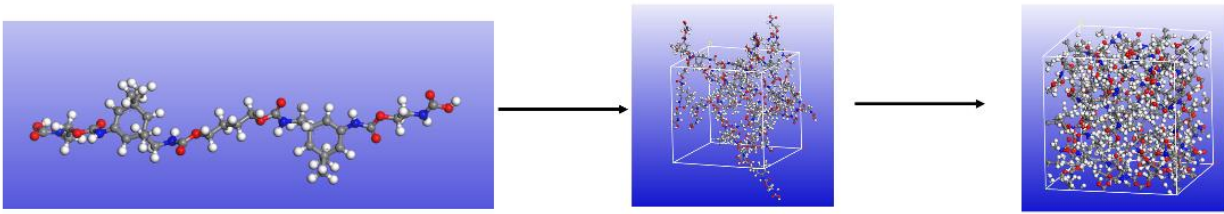

Hard segment

3D Periodic Boundary Condition

Molecular Dynamics Simulation

(b)

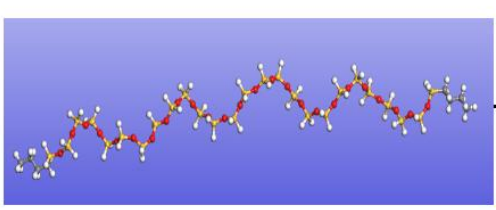

Soft segment
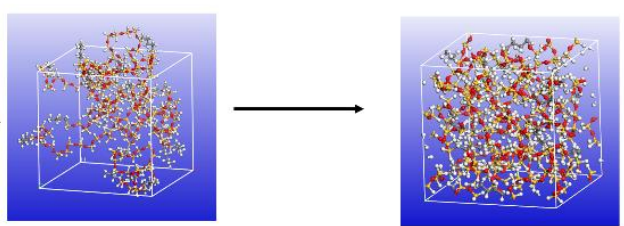

3D Periodic Boundary Condition

Molecular Dynamics Simulation

Figure S13. Simulation strategies of a) soft segment and b) hard segment. 


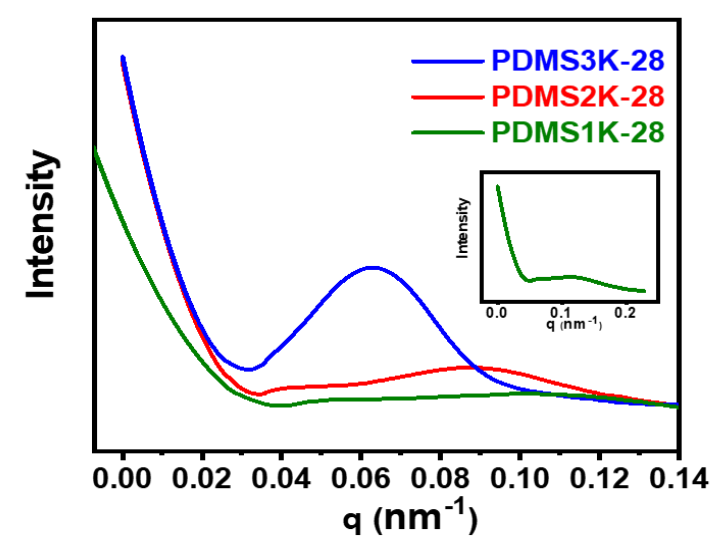

Figure S14. 1D SAXS curves of the Si-TPUs with different $M_{n}$ of SS. The inset is PDMS1K-28 with an SD of $1670 \mathrm{~mm}$. The signal intensity gradually increases with increase in the value of $M_{n}$ of SS, simultaneously, q gradually decreases.
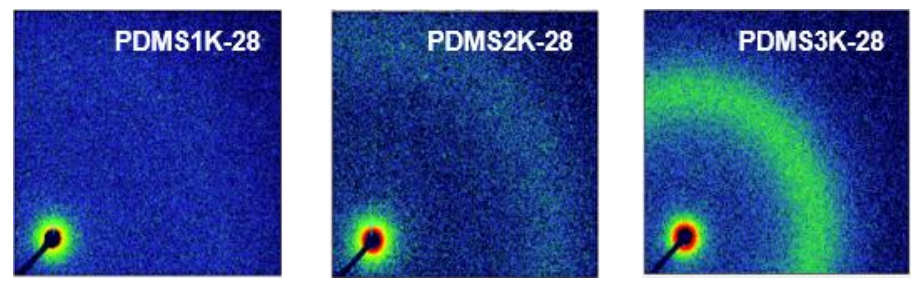

Figure S15. 2D SAXS pattern of the Si-TPUs with different $M_{n}$ of SS. The scatter ring gradually becomes apparent, supporting the conclusion of Figure S14, Supporting Information.

Table S3. Periodicity (D) of Si-TPUs.

\begin{tabular}{lll}
\hline Sample code & $\mathrm{q}\left(\mathrm{nm}^{-1}\right)$ & $\mathrm{L}(\mathrm{nm})$ \\
\hline PDMS1K-28 & 0.1170 & 53.7 \\
PDMS2K-19 & - & - \\
PDMS2K-23 & 0.0965 & 65.1 \\
PDMS2K-28 & 0.0858 & 73.2 \\
PDMS2K-33 & 0.0802 & 78.3 \\
PDMS2K-39 & 0.0692 & 90.8 \\
PDMS3K-28 & 0.0628 & 100.0 \\
\hline
\end{tabular}



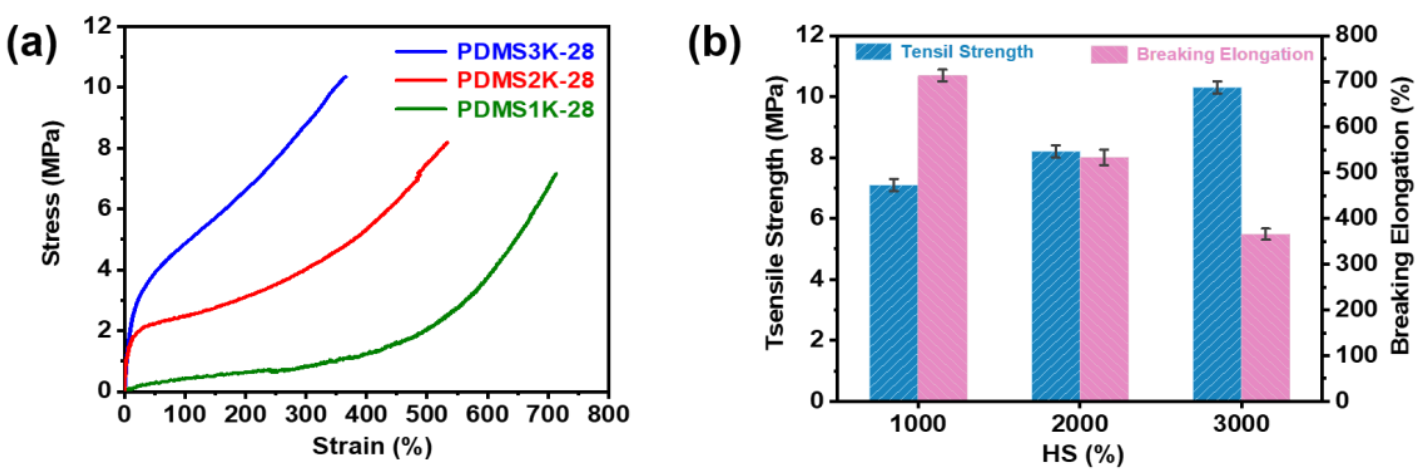

Figure S16. Mechanical properties of Si-TPUs. a) Representative stress-strain curves of Si-TPUs with different $M_{n}$ of SS. b) A histogram of tensile strength and elongation at break of Si-TPUs with different $M_{n}$ of SS.

Table S4. Summary of the mechanical performance values of Si-TPUs.

\begin{tabular}{cccccc}
\hline $\begin{array}{c}\text { Sample } \\
\text { code }\end{array}$ & $\begin{array}{c}\text { Tensile } \\
\text { strength } \\
\text { (MPa) }\end{array}$ & $\begin{array}{c}\text { Breaking } \\
\text { elongation (\%) }\end{array}$ & $\begin{array}{c}\text { Stress at 100\% } \\
\text { elongation (MPa) }\end{array}$ & $\begin{array}{c}\text { Stress at 300\% } \\
\text { elongation (MPa) }\end{array}$ & $\begin{array}{c}\text { Toughness } \\
\left(\mathrm{MJ} \mathrm{m}^{-3}\right)\end{array}$ \\
\hline PDMS1K-28 & $7.1 \pm 0.2$ & $713 \pm 13$ & 0.4 & 0.8 & 13.0 \\
PDMS2K-19 & $1.3 \pm 0.1$ & $956 \pm 20$ & 0.2 & 0.3 & 5.2 \\
PDMS2K-23 & $6.2 \pm 0.3$ & $741 \pm 15$ & 0.8 & 1.8 & 20.5 \\
PDMS2K-28 & $8.2 \pm 0.2$ & $534 \pm 17$ & 4.8 & 6.4 & 22.0 \\
PDMS2K-33 & $13.1 \pm 0.3$ & $458 \pm 10$ & 6.3 & 9.6 & 39.5 \\
PDMS2K-39 & $20.3 \pm 0.2$ & $378 \pm 13$ & 10.5 & 17.4 & 52.8 \\
PDMS3K-28 & $10.3 \pm 0.2$ & $366 \pm 12$ & 4.9 & 8.8 & 23.3 \\
\hline
\end{tabular}


(a)

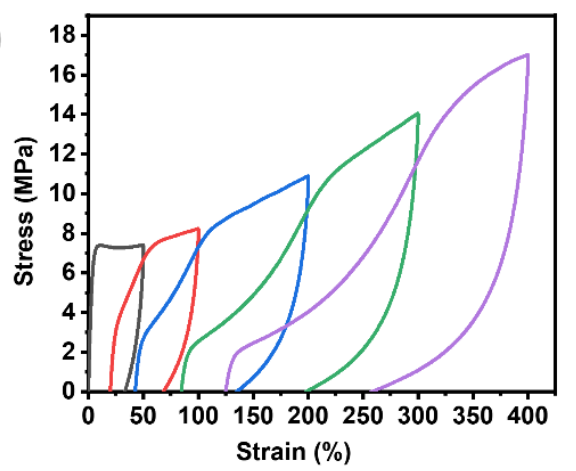

(b)

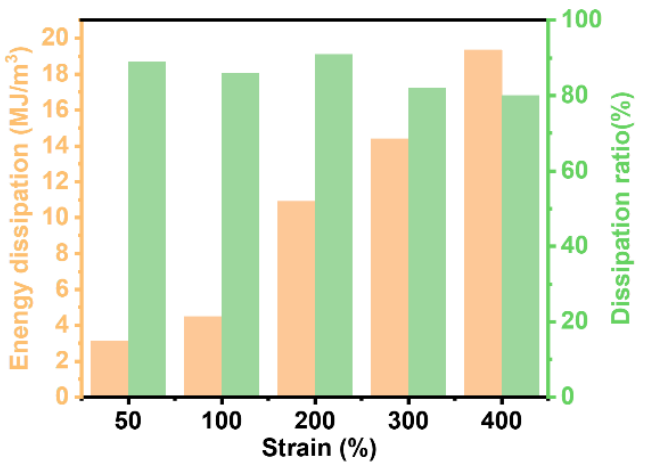

Figure S17. a) Cyclic tensile curves of PDMS2K-39 within the maximum strain scope of $50-400 \%$. The increase in the area of the hysteresis loop represents an enhancement in the energy dissipation capacity. b) Energy dissipations and dissipation ratios at different maximum strains. The dissipation ratio is the ratio between the energy dissipation and load energy (area under the loading curve).
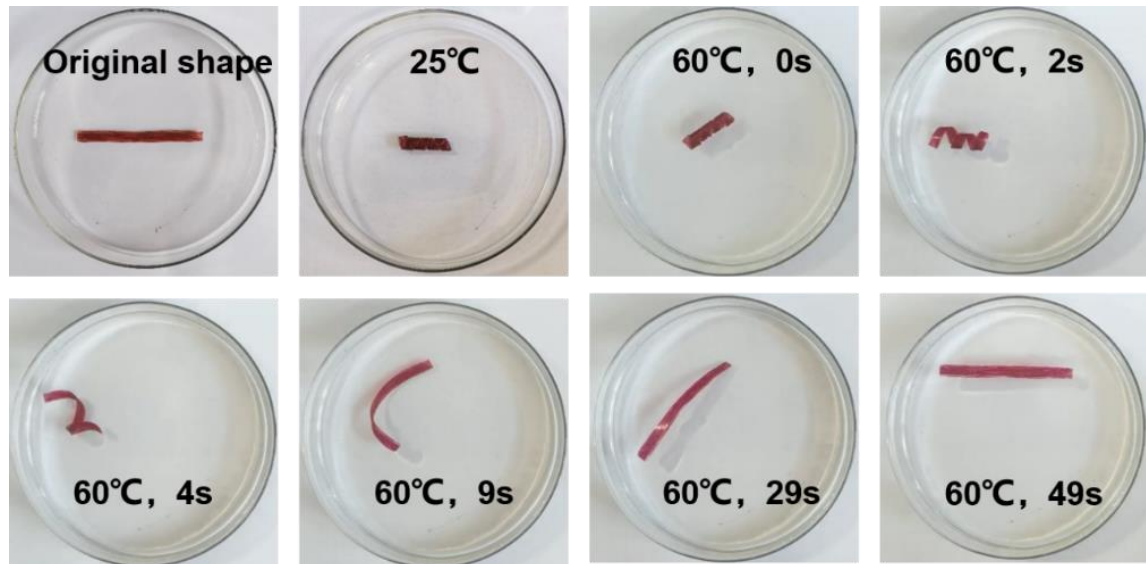

Figure S18. Macroscopic performance of the shape memory effect of PDMS2K-28 from a temporary twisted shape to a perpetual straight shape in water at $60{ }^{\circ} \mathrm{C}$. 


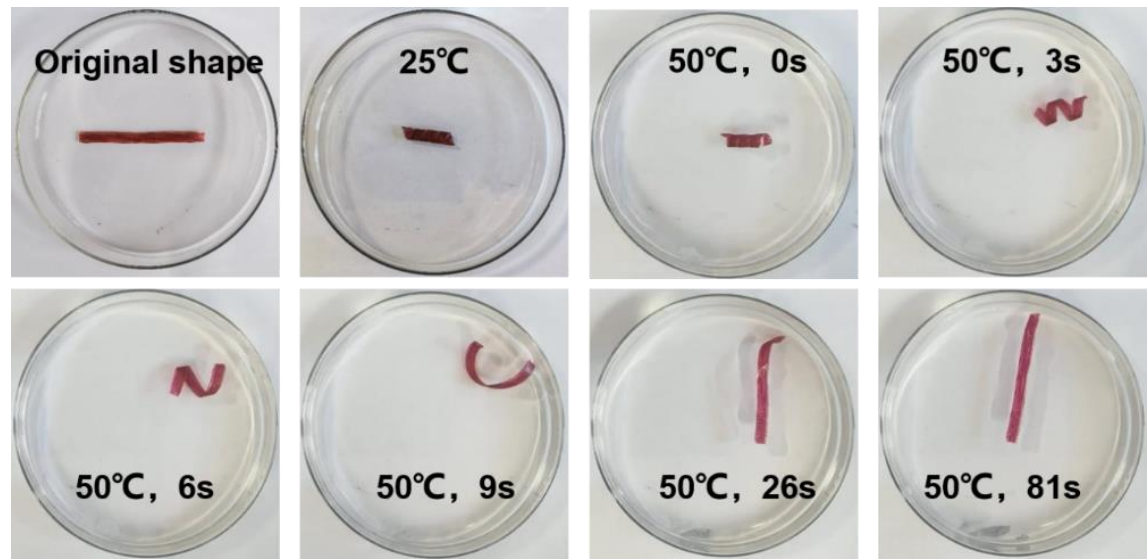

Figure S19. Macroscopic performance of the shape memory effect of PDMS2K-28 from a temporary twisted shape to a perpetual straight shape in water at $50{ }^{\circ} \mathrm{C}$.
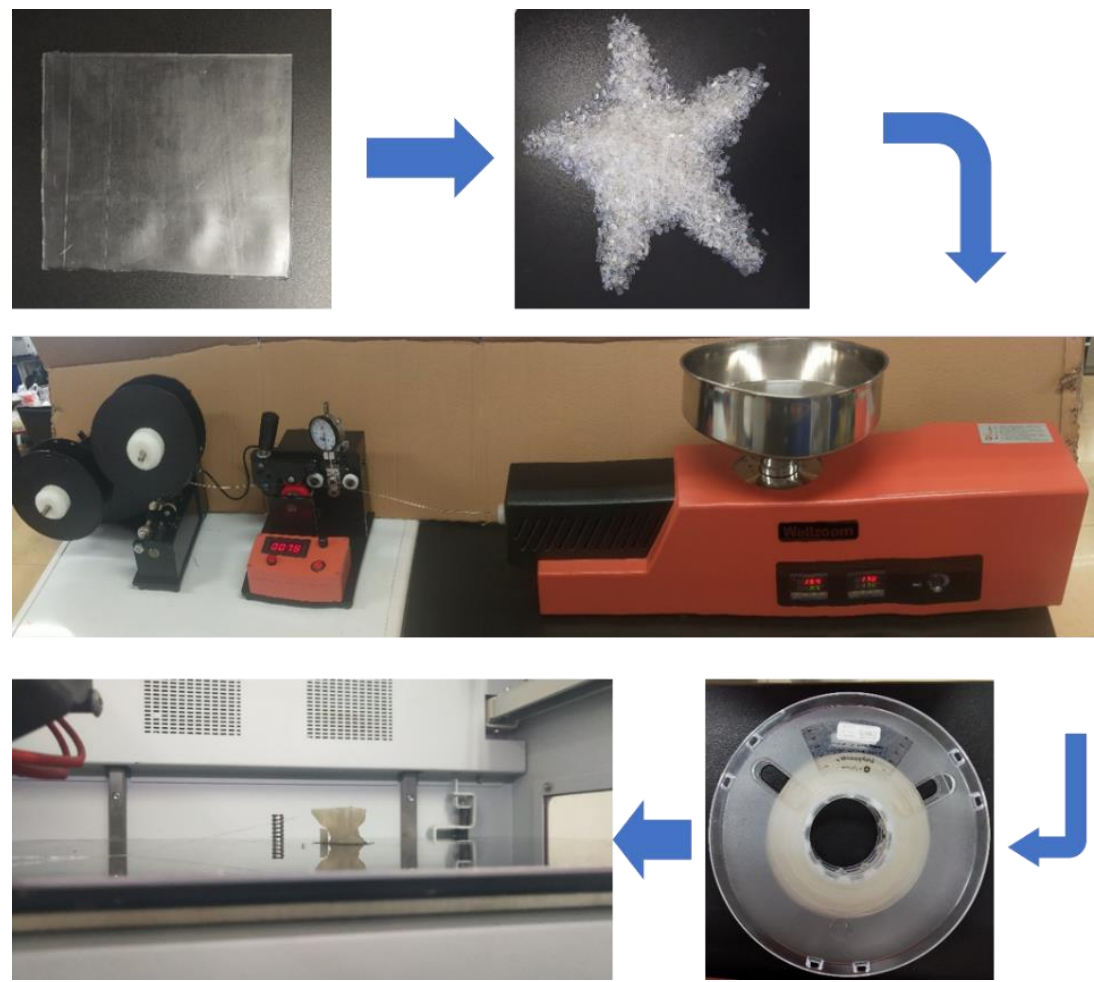

Figure S20. Flowchart of PDMS2K-39 for 3D printing. 